\title{
Erratum to: Influence of response shift on early patient-reported outcomes following autologous chondrocyte implantation
}

\author{
Jennifer S. Howard • Carl G. Mattacola • \\ David R. Mullineaux • Robert A. English • \\ Christian Lattermann
}

Published online: 17 October 2013

(c) Springer-Verlag Berlin Heidelberg 2013

\section{Erratum to: Knee Surg Sports Traumatol Arthrose \\ DOI 10.1007/s00167-013-2654-1}

Unfortunately, the references in the last two rows/columns entries were incorrectly cited in the original publication of Table 1. Corrected reference numbers are given below in brackets.

Minimal detectable change at 6 months $15.6[15] \quad 14[22] \quad 8.3[15] \quad 10.9[15]$

Minimal detectable change at 12 months $13.7[15] \quad 14[22] \quad 6.6[15] \quad 15.3[15]$

The online version of the original article can be found under doi:10.1007/s00167-013-2654-1.

\section{J. S. Howard ( $\square)$}

Department of Rehabilitation Sciences, University of Kentucky, Lexington KY, Wethington Building, Room 206B, 900 South Limestone, Lexington, KY 40536-0200, USA

e-mail: J.S.Howard@uky.edu

\section{J. S. Howard}

Department of Orthopaedics and Sports Medicine, University of Kentucky, Lexington KY, Wethington Building, Room 206B, 900 South Limestone, Lexington, KY 40536-0200, USA

C. G. Mattacola

Division of Athletic Training, Department of Rehabilitation Sciences, University of Kentucky, Wethington Building, Room 210E, 900 South Limestone,

Lexington, KY 40536, USA
D. R. Mullineaux

School of Sport and Exercise Science, College of Social Sciences, University of Lincoln, Brayford Pool, Lincoln, Lincolnshire LN6 7TS, UK

\section{R. A. English}

Division of Physical Therapy, Department of Rehabilitation Sciences, University of Kentucky, Room 204S Wethington Building, 900 South Limestone Street, Lexington, KY 40536, USA

C. Lattermann

Department of Orthopaedic Surgery and Sports Medicine, Center for Cartilage Repair and Restoration Medical Center, University of Kentucky, Kentucky Clinic K401, 740 South Limestone, Lexington, KY 40536, USA 